\title{
On the Partial PUBlic PROVISION OF A PRIVATE GoOD
}

\author{
RAJSHRI JAYARAMAN
}

CESIFO WORKING PAPER NO. 811

CATEgory 1: Public FinANCE

DECEMBER 2002

\footnotetext{
An electronic version of the paper may be downloaded

- from the SSRN website: www.SSRN.com

- from the CESifo website: www.CESifo.de
} 


\title{
ON THE PARTIAL PUBLIC PROVISION OF A PRIVATE GOOD
}

\begin{abstract}
When the public provision of private goods is partial rather than universal, public supply may be supplemented by the entry of private firms in the market for the private good. The main purpose of this paper is to explore whether partial public provision helps or hinders aggregate access to the private good by exploring the effect of public provision on that of private firms. We find that the outcome depends on such things as the targeting of public provision, market structure, and the level of public provision.
\end{abstract}

JEL Classification: H4, D4.

Rajshri Jayaraman

CESifo (University of Munich \&

Ifo Institute)

Poschingerstrasse 5

81679 Munich

Germany

Jayaraman@cesifo.de

I thank seminar participants of CES and Daniel Sturm for useful comments and suggestions. 


\section{Introduction}

Most governments spend large sums of money on the provision of private goods. Some goods, such as schooling in the US and health care in the UK, are provided universally, in the sense that anyone who wishes to avail themselves to the good can do so free of charge. Others, such as day care in most OECD countries and schooling in many developing countries, tend to be offered in limited supply by the public sector, often at a highly subsidised rate. Under universal provision, there is obviously no residual market for a private firm. When public provision is only partial, however, it is sometimes supplemented by the entry of private firms in the market for the private good.

Although there is no general consensus that goods such as secondary school and day care should be universally provided, they are distinct from other types of private goods in that they are not pure consumption goods. They often play an important role in expanding income earning opportunities. This is clearly the case with education. Similarly, consumption of day care services is often critical in enabling (often female) labour force participation. This means not only that understanding the determinants of aggregate provision of these goods has important implications for such phenomena as income and employment, but also that governments often have an interest in expanding their provision, quite aside from any positive externalities with which they may be associated.

Often, governments presume that this can be accomplished simply by expanding public provision. Such an expansion, however, has two effects. On the one hand, it has the direct effect of increasing supply. On then other hand, it affects private firm's provision. Since aggregate provision is the sum of private and public provision, the net effect is therefore ambiguous.

The main purpose of this paper is to explore whether partial public provision of a private good helps or hinders aggregate access, by exploring the effect of public provision on that of private firms. In particular, we address such positive questions as how does a change in government provision affect private supply and price? Is there crowding out of the private sector by the 
public sector? Does the effect of public on private provision vary depending on market structure or the targeting of public provision? We also address the normative issue of the extent to which a government interested in achieving a certain level of aggregate provision should directly provide.

The idea that public provision affects private provision is obviously not new. It dates at least as far back to the old debate in macroeconomics between Friedman and Keynes regarding whether or not an increase in government expenditure is expansionary (see, for example, Friedman (1962) p. 79-81.) The theoretical literature in public economics may be divided into four general groups. One strand of the literature is public finance oriented. dealing with normative considerations surrounding redistribution and efficiency (Besley and Coate, 1991). Another line of the literature deals with the political economy of public provision. It asks the positive question of how much public provision will be observed within the context of voting models (Epple and Romano (1996a, b) and Blomquist and Christiansen (1999)). Both these strands of literature are concerned primarily with the role of public provision as a means of redistribution. It is natural, therefore, that their focus should be on the determinants of public provision. Our focus in this paper, by contrast, is on the determinants of private provision. Consequently, we will abstract altogether from such issues as taxation and the political process which determines the level of public provision. We will be concerned with both positive and normative aspects of public provision, but only in so far as they affect private provision by firms and thereby aggregate access to the private good.

A third line of the literature is concerned with the effect of public provision on private provision in the form of voluntary contributions (Andreoni (1993) and Bernheim (1986)). In this paper the focus is on private rather than public goods, and private firms rather than voluntary contributions. As such. it is more closely related to the industrial organisation literature on demand rationing and firm entry. ${ }^{1}$ The strand of the IO literature concerned with

\footnotetext{
${ }^{1}$ See Tirole, 1988, Chapters 5 and 8 for a review.
} 
the effect of government policy on private firm strategies (such as pricing and entry) typically does not address the impact on private firms of government provision, but of other government policies such as subsidies, government regulation or market protection.

The theoretical literature on the crowding out of the private sector by the public sector is scant. The only paper of which the author is aware is Shmanske (1996). Like him, we too are interested in the extent to which government provision crowds out entry of private firms. However, our papers differ in at least two important ways, both of which are contained in the title of his paper: namely queuing and contestability. We do not delve into queuing as a means of rationing government provided services, although we do discuss alternative rationing rules. Furthermore, firm entry in the markets in which we are interested typically entails incurring a fixed cost and is modeled as such; therefore, these markets would not be contestable, even in the absence of government provision.

Despite the dearth of a theoretical literature, there is a growing empirical. policy-oriented literature on the effect of public on private provision (see James (1993) and Jimenez and Sawada (2001) on education, and Filmer, Hammer and Pritchett (2000) on health care, and Kamerman (2000) on day care.) This paper makes a small stride in formalising some of the observations made in these papers and these will be highlighted at appropriate points later on.

Section 2 presents the basic model and introduces some notation. Section 3 characterises the firm's optimal entry and pricing strategy given government provision. Section 4 presents a positive analysis regarding the effect of a change in the level and price of subsidised government provision on aggregate provision, and also some further comparative statics results. It also provides some normative analysis regarding the efficient expansion of aggregate provision. Section 5 discusses the effect of government provision on aggregate provision when the former is intended to target the poor. Finally, Section 6 concludes. 


\section{The Model}

Consider a market for a private good consisting of the government and a private provider on the supply side, and a continuum of agents on the demand side, with names on the unit interval. Each agent demands either one or zero units of the good. So, if the good is day care, a parent either sends their child to day care or not; if the good is education, one either does or does not obtain schooling. If an agent chooses not to consume the good $(\alpha=0)$, she obtains an income (equivalent) of $m \geq 0$, which is the same across all agents. For a parent, this can be interpreted as the pleasure of staying home and caring for one's child oneself. In the case of education, this may be viewed as the wage for an unskilled worker.

If, instead, she chooses to consume the good ( $\alpha=1)$, she has a (known) potential post-tax labour market income of $W \in[\underline{W}, \bar{W}]$, where $W \sim G(W)$, $0 \leq \underline{W}<\bar{W}<\infty$, and $\bar{W}>m$. $G$ is a thrice continuously differentiable cumulative distribution function with a positive density $g=G^{\prime}$ everywhere on $[\underline{W}, \bar{W}]$ (Assumption 1). Let $w=W-m, \bar{w}=\bar{W}-m$, and $\underline{w}=\underline{W}-m$. Then, there exists a cdf $F(w)$ such that $F(w)=G(W)$ and for $w \in\lceil\underline{w}, \bar{w}\rceil$, $F$ satisfies Assumption 1. Utility is linear in consumption $x$. So, if the price of the good is $p$ then:

$$
u(x)=\left\{\begin{array}{cc}
m & \text { if } \alpha=0 \\
W-p & \text { if } \alpha=1
\end{array}\right.
$$

From equation (1), it is clear that given a price $p, \alpha=1(\alpha=0)$ if $p<w$ $(p \geq w)$.

The government provides the private good for a proportion $q \in[0,1]$ of all agents, at a price of $p_{g}{ }^{2}$ Partial public provision is therefore captured in $p_{g}>\underline{w}$ or $q \in(0,1)$. The level and price of the publicly provided good is

\footnotetext{
${ }^{2}$ We abstract from how government provision is financed. Since our focus is not on redistribution, this need not be restrictive: $W$ reflects post-tax income, so any change in $q$ or $p_{q}$ can be interpreted as reflecting a change in the allocation of government expenditure given a particular tax structure.
} 
chosen by the government (perhaps as the result of some political process) and taken as exogenous by private providers.

There is a single private provider, who is a potential entrant in the market for the private good. Since the private sector in markets for such goods as health care, education or day care is dominated by either non-profit agencies or local monopolists, we will consider two separate cases: one in which the private provider is a profit maximising monopolist (henceforth "profit maximiser") and another in which the firm is a non-profit. ${ }^{3}$ In either case, this private firm faces a fixed cost of entry $0<B<\bar{w}-c$, where $c>0$ is the marginal cost. ${ }^{4}$ We also assume that $\frac{2 f(p)}{f^{\prime}(p)}+p>c$ for all $p \in[c, \bar{w}]$, (Assumption 2), which will later guarantee the uniqueness of a solution to the firm's problem. ${ }^{5}$

A good provided by the government and the private firm are perfect one to one substitutes. This means that consumers wishing to buy the good would ideally like to do so from whomever offers it at the cheaper price. So, for a given $\left(q, p_{g}\right)$, a firm which offers the good for a price $p$ faces the following demand function:

$$
D(p)=\left\{\begin{array}{cc}
1-F(p) & \text { if } p<p_{g} \\
\max \left\{\frac{1-F(p)}{2}, 1-F(p)-q\right\} & \text { if } p=p_{g} \\
\max \{1-F(p)-q, 0\} & \text { if } p>p_{g}
\end{array}\right.
$$

The three equations in (2) respectively describe scenarios in which the firm is the sole provider catering to all individuals with incomes greater than

\footnotetext{
${ }^{3}$ The results pertaining to the non-profit firm are analogous to those for a representative firm operating in a perfectly competitive market. The two cases may therefore be viewed as representing either end of the spectrum of market concentration.

${ }^{4}$ With a continuum of agents, $B$ is interpreted as a per capita fixed cost.

${ }^{5}$ This is not as restrictive a condition as it may seem: a sufficient condition is that $\frac{2 f(p)}{f^{\prime}(p)}$ be non-decreasing. In the case of a uniform distribution, therefore, this condition is automatically satisfied. Income is more commonly distributed lognormally. When this is the case, the condition is satisfied if $\bar{w}<e^{\left(\mu_{w}-\sigma_{w}^{2}\right)}$.
} 
$p$; the government and the firm offer the same price and split the market equally or, when government supply cannot cater to at least half the market at a price of $p_{q}$, the firm caters to residual demand; and the government's price is lower than the firm's, with the firm catering to residual demand.

The second and third cases in equation (2) assume that there is efficient rationing in the sense that those with higher labour market earnings obtain the private good at the cheaper government institution. This is not a trivial assumption and will be relaxed in Section 6 where we consider alternative rationing rules. However, it is often an accurate characterisation of the residual demand faced by firms in these types of markets, particularly in developing countries where wealthier individuals often do benefit disproportionately from public spending (see, for example, Filmer, Hammer and Pritchett, 2002). More generally, in the context of a queuing model, this would be a natural outcome if the value of time were the same for all individuals: those who are most eager to consume the good - those with the highest $w s$ - would end up at the front of the queue for the cheaper government-provided good.

Since we are concerned with the private sector response to government provision (and since the latter tends to be politically determined), the government is treated as a passive agent in this model. A strategy for the firm then comprises an entry decision $e\left(p_{g}, q\right) \in\{0,1\}$ and pricing decision $p\left(p_{g}, q\right)>0$. If the firm is a profit maximiser, these solve:

$$
\max _{e \in\{0,1\}, p>0} \pi(e, p)=e[D(p)(p-c)-B]
$$

If the firm is a non-profit institution (without access to outside sources of funding) interested in expanding access to the private good, it will price at the minimum price such that profits are equal to zero, and enter so long as demand is large enough to sustain such a price. ${ }^{6}$ For all future reference, we

\footnotetext{
${ }^{6}$ The assumption that the non-profit prices at set as low as possible without making a loss is intended to reflect both the fact that these providers tend to be interested in reaching many people and are often motivated by reaching poorer segments of the population.
} 
denote solutions to the profit-maximising firm's problem by $p^{*}$ and $e^{*}$ and solutions to the non-profit firm's problem by $p^{0}$ and $e^{0}$.

Before proceeding to the analysis, we introduce some notation. First, denote by $\pi^{j}(p)$ the firm's profits when it enters and prices at $p<p_{g}(j=1)$, at $p=p_{q}(j=2)$ and $p>p_{q}(j=3)$. So, the firm's profit in each of these three cases is:

$$
\begin{aligned}
\pi^{1}(p) & = & (1-F(p))(p-c)-B \\
\pi^{2}(p) & = & \max \left\{\left(\frac{1-F(p)}{2}\right), 1-F(p)-q\right\}(p-c)-B \\
\pi^{3^{\prime}}(p) & = & \max \{1-F(p)-q, 0\}(p-c)-B
\end{aligned}
$$

Notice from equation (6) that when $\max \{1-F(p)-q, 0\}=0$, a firm will never choose to enter the market for the private good. So, we can focus on:

$$
\pi^{3}(p)=(1-F(p)-q)(p-c)-B
$$

The maximum profit a firm could earn upon entry under each of these scenarios is $\pi^{j *}=\pi^{j}\left(p_{j}^{*}\right)$, where:

$$
p_{j}^{*}=\arg \max \pi^{j}(p)
$$

This is the price a profit-maximising firm will choose upon entry. A nonprofit firm choosing to enter will, by contrast, price at:

$$
p_{j}^{0}=\min p: \pi^{j}(p)=0 .
$$

To make the problem interesting, we will assume that $\pi^{1 *}>0$ (Assumption 3). This means that there will exist some circumstances in which a profit-maximiser will have an incentive to enter the market.

Interpreted as a representative competitive firm, pricing at average cost would be the equilibrium firm strategy. 


\section{$3 \quad$ Entry and Pricing}

Our primary interest in this paper is to explore the effect of government provision on aggregate access. From the demand equation (2) above, it should be clear that this is going to be driven by the effect of government provision on the firm's entry and pricing decision. We begin this section by introducing some basic results which we will go on to use in the full characterisation of the firm's equilibrium entry and pricing strategies.

\subsection{Preliminaries}

Lemma 1 below will ensure the existence of a solution to the firm's pricing problem, conditional on entry.

Lemma 1 (i) $\pi^{j}(p)$ is twice continuously differentiable on $\lceil c, \bar{w}\rceil$ for $j=1,3$; (ii) $p_{j}^{0}, p_{j}^{*} \in[c, \bar{w}]$ if $e^{*}=1$.

\section{Pronf}

$p$ and $F(p)$ are continuous. Since the product of continuous functions is continuous, as is the sum of continuous functions, continuity follows from equations (4) and (7). Differentiability follows from Assumption 1. This completes the proof for part (i).

For part (ii), consider first a non-profit firm for which $p^{0}=c+\frac{B}{D\left(p^{0}\right)}$. Since $D(p)$ reaches a maximum at $D(p)=1, p^{0} \geq c+B$. At the other end, suppose $p^{0}>\bar{w}$. Then $D\left(p^{0}\right)=0$ and $\pi\left(p^{0}\right)=-B$, which is strictly dominated by $e=0$ and this is a contradiction.

For a profit-maximiser, suppose not. Suppose that $e^{*}=1$ and $p_{j}^{*}<c$. This means that $F\left(p_{j}^{*}\right) \in[0,1)$. From equations $(4),(5)$ and $(7)$, note that $\pi^{1} \geq \pi^{2}, \pi^{3}$. Therefore, since $\pi^{1 *}=\left(1-F\left(p_{1}^{*}\right)\right)\left(p_{1}^{*}-c\right)-B<0$, $\pi^{2 *}, \pi^{3 *}<0$. In each of these three cases, therefore the firm could have earned $\pi=0$ by choosing $e=0$ and this is a contradiction. Suppose now that $e^{*}=1$ and $p_{j}^{*}>\bar{w}$. Then, $F\left(p_{j}^{*}\right)=1$ and $\pi^{1 *}=-B$, leading to a similar contradiction. 
Lemma 1 states that any firm which chooses to enter will price at a level between the marginal cost and highest potential incomes. For our purposes. it means that in solving the firm's maximisation problem (conditional on entry), we can restrict attention to $p \in[c, \bar{w}]$. Since (also by Lemma 1), profits are continuous over this range, there exists a $p$ which maximises equations (4) and (7) for the profit-maximiser. Lemma 1 combined with assumption 3 also guarantee the existence of $p_{1}^{0}$, which means that, under certain circumstances, a non-profit will also have an incentive to enter the market. Furthermore, when they exist, assumption 2 guarantees that the optima described in equations (8) and (9) are unique for $j=1,3$.

None of the lessons drawn from Lemma 1 have made any reference to the case where the firm prices at the same level as the government $(j=2)$. Lemma 2 explains why this case can be ignored in the presence of government provision.

\section{Temma 2}

For both the profit-maximiser and the non-profit, entering and pricing at $p=p_{g}$ is a strictly dominated strategy for $q>0$

\section{Proof}

For a profit-maximiser, we claim that entering and pricing at $p_{g}$ is strictly dominated by pricing at $p=p_{g}-\epsilon \quad \forall p_{q}>c, q>0 \quad \epsilon>0$ and small. It suffices to show that $\pi^{1}\left(p_{g}-\epsilon\right)>\pi^{2}\left(p_{g}\right) \quad \forall p_{g}>c$ Notice from (4) and (5) that $\pi^{1}(p)>\pi^{2}(p) \quad \forall p>c, q>0$, and as a result

$$
\lim _{\epsilon \rightarrow 0} \pi^{1}\left(p_{g}-\epsilon\right)=\pi^{1}\left(p_{g}\right)>\pi^{2}\left(p_{g}\right)
$$

For a non-profit, there are two possible scenarios: $p_{g}>p_{1}^{0}$ and $p_{g} \leq p_{1}^{0}$. In former case, clearly the non-profit's optimal strategy is to enter and price at $p^{0}=p_{1}^{0}$. In the second case, pricing at $p^{0}=p_{g}$ would entail making a loss. The firm would therefore be better off not entering the market at all. 
It follows from Lemma 2 that a firm will never price at $p=p_{g}$. Indeed. this is a testable implications of this model. In terms of the analysis in this paper, this means that we can restrict our attention to scenarios 1 and 3 in which the private firm is the sole provider of the private good, pricing below $p_{g}$, and one in which the private provider caters to residual demand, pricing at $p>p_{g}$. Lemma 2 therefore gives us some indication of a firm's pricing strategy. Lemma 3 elaborates on this and also tells us something about its entry decision.

\section{Lemma 3}

There exists a unique $\bar{q} \in(0,1)$ such that $\pi^{3 *}(\bar{q})=0, \pi^{3 *}(q) \leq 0 \quad \forall q \geq \bar{q}$ and $\pi^{3 *}(q)>0 \quad \forall q<\bar{q}$.

\section{Proof}

$\pi^{3 *}(q)=\left(1-F\left(p_{3}^{*}\right)-q\right)\left(p_{3}^{*}-c\right)-B$ is continuous in $q$, with $\pi_{q}^{3 *}<0 \quad \forall p \in[c, \bar{w}]$. Since $\pi^{3 *}(0)>0$ by assumption 3 and $\pi^{3 *}(1)<0$, by the intermediate value theorem, the result follows.

This Lemma has two related implications. First, there exists a (no) $p_{3}^{0}$ for $q \leq \bar{q} \quad(q>\bar{q})$. Second, when government provision is high $(q \geq \bar{q})$, it will never be worthwhile for a firm to enter and price at a level which entails sharing the market with the government: profit-maximisers would make a loss and there exists no solution to the non-profit's problem. This result basically captures the idea that above a certain level of public provision. private provision is completely crowded out, and this level $(\bar{q})$ is the same for a profit-maximiser and a non-profit.

As we will see in proposition 1 below, given $q$, the non-profit's strategy depends solely on whether the government price is above or below $p_{1}^{0}$. The profit maximiser's problem is a slightly more complicated function of government prices for low levels of government provision, as Lemma 4 demonstrates. 


\section{I.emma 4}

For a given $q<\bar{q}$ there exists a unique $\tilde{p}(q) \in\left[p_{1}^{0}, p_{1}^{*}\right\rceil$ such that

$$
\pi^{1}(p)\left\{\begin{array}{lll}
>\pi^{3 *}(q) & \text { if } & p>\tilde{p}(q) \\
=\pi^{3 *}(q) & \text { if } & p=\tilde{p}(q) \\
<\pi^{3 *}(q) & \text { if } & p<\tilde{p}(q)
\end{array}\right.
$$

\section{Proof}

By Lemma 1 and Assumptions 1 and $2, \pi^{1}(p)$ is continuous and strictly increasing on $\left[p_{1}^{0}, p_{1}^{*}\right]$. Since, by assumption $3, \pi^{1 *}>0, p_{1}^{0}$ exists; $\pi^{1}\left(p_{1}^{0}\right)<\pi^{3 *}(q)$ for $q<\bar{q}$ and (4) and (7) reveal that $\pi^{1}\left(p_{1}^{*}\right)>\pi^{3 *}(q)$. Therefore, by the intermediate value theorem, there exists a unique $\tilde{p}(q)$ which satisfies equation (10).

Lemma 4 says that for low levels of government provision there exists a threshold government price above which the profit-maximising firm will enter, undercut the government price and capture the entire market; and below which it will price higher than the government and cater to residual demand. Figure 1 illustrates two hypothetical profit functions. The solid line profit function is one in which the firm is the sole provider. In the dashed one, the firm shares the market with the government. Note that at positive levels, profits are strictly lower the larger is government provision. As Lemma 3 notes, when $q>\bar{q}$, the entire profit curve falls under the x-axis. Figure 1 also illustrates $\tilde{p}(q)$, which will crop up in the next section when we describe the profit-maximiser's equilibrium strategy.

Armed with these four lemmas, we are now prepared to fully characterise a firm's equilibrium pricing and entry strategies for a given level of public provision. 


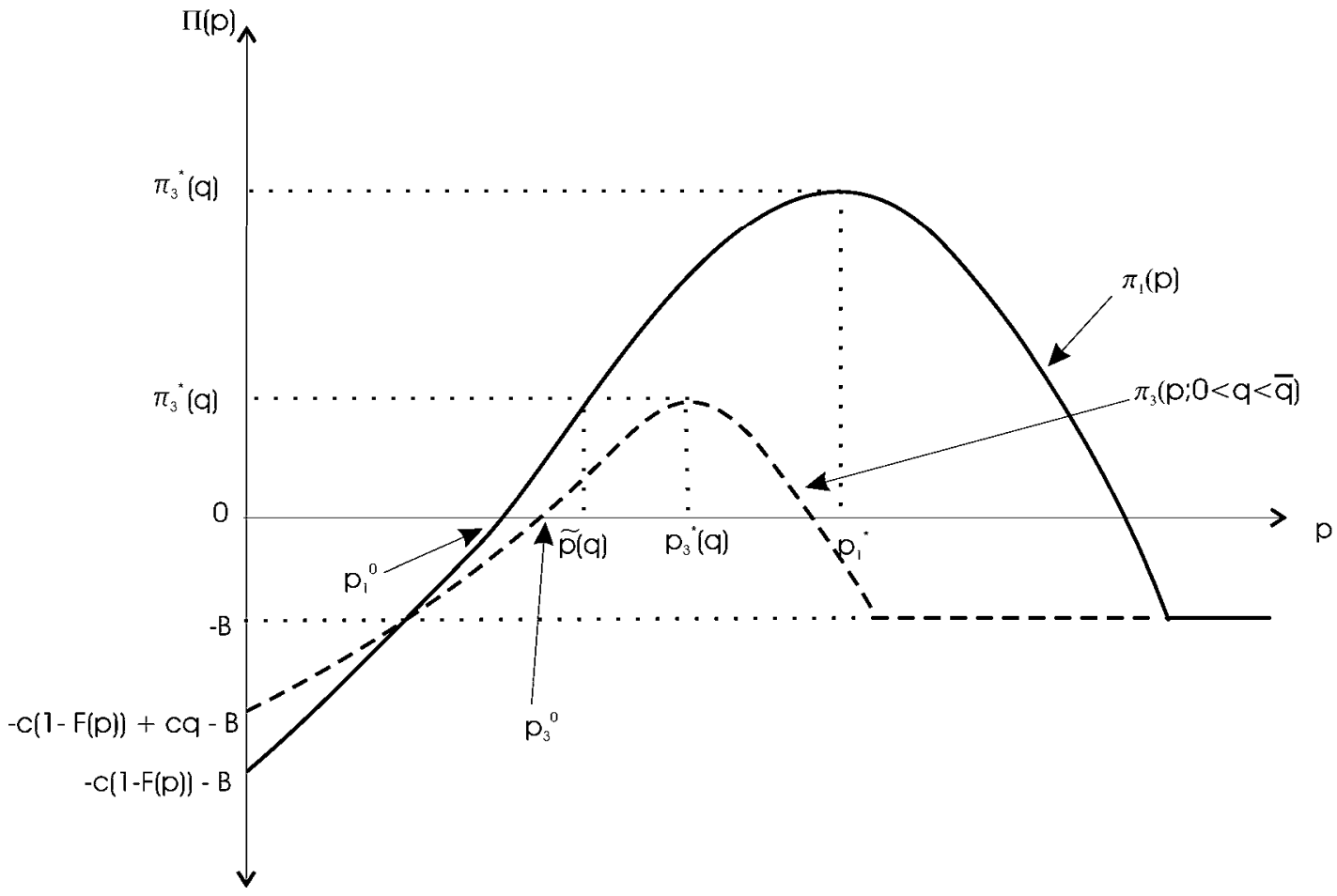

Figure 1: Profit Function, Conditional upon Entry

\subsection{Equilibrium Strategies}

\subsubsection{Non-profit Firm}

In light of the previous section, the pricing and entry policy of the non-profit firm is rather straightforward. When the level of government-provision is too high $(q \geq \bar{q})$, the non-profit will only find it worthwhile to enter when the government's price is high enough to enable it to corner the entire market. So, it will choose the following strategy: ${ }^{7}$

$$
\left(e^{0}, p^{0}\right)=\left\{\begin{array}{lll}
\left(1, p_{1}^{0}\right) & \text { if } & p_{g}>p_{1}^{0} \\
(0, p) & \text { if } & p_{g} \leq p_{1}^{0}
\end{array}\right.
$$

\footnotetext{
${ }^{7}$ The price chosen in the case of no entry is immaterial.
} 
When government provision is low enough $(q<\bar{q})$, the non-profit may choose to either price low enough to be the sole provider, or price at a slightly higher level and share the market with the government. In particular:

$$
\left(e^{0}, p^{0}\right)=\left\{\begin{array}{lll}
\left(1, p_{1}^{0}\right) & \text { if } & p_{g}>p_{1}^{0} \\
\left(1, p_{3}^{0}(q)\right) & \text { if } & p_{g} \leq p_{1}^{0}
\end{array}\right.
$$

The non-profit firm's strategy is summarised in the following proposition:

Proposition 1 A non-profit firm's optimal strategy is described by (11) for $q \geq \bar{q}$ and by (12) for $q<\bar{q}$.

\section{Proof}

The existence and uniqueness of $p_{1}^{0}$ and $p_{3}^{0}(q)$ is guaranteed by Lemmas 1 and 4 , and the assumption that $\pi^{1 *}>0$. By Lemma 2, pricing at $p^{0}=p_{q}$ is a strictly dominated strategy, so we can eliminate $p_{2}^{0}=p_{g}$ from contention. A non-profit firm choosing to enter will therefore price at $p^{0} \in\left\{p_{1}^{0}, p_{3}^{0}(q)\right\}$. The lowest possible price a non-profit can offer is $p_{1}^{0}$; this is an equilibrium price when the firm captures the entire market, i.e. when $p_{g}>p_{1}^{0}$. Therefore, a firm's optimal strategy in this case is clear, irregardless of $q$. When $q \geq \bar{q}$, by Lemma 3 the non-profit will never enter and share the market, thereby explaining the second part of (12). Conversely, when $q<\bar{q}$, by Lemma 4 , the firm will opt to share the market with the government when $p_{g} \leq p_{1}^{0}$, i.e. when its first-best option of having exclusive access to the market, is not available.

\subsubsection{Profit-maximising Monopolist}

For the profit-maximiser, things are only slightly more complicated depending on the government price. When government provision is large $(q \geq \bar{q})$, the firm will only enter when it can corner the entire market. That is, when government provision is high: 


$$
\left(e^{*}, p^{*}\right)=\left\{\begin{array}{lll}
\left(1, p_{1}^{*}\right) & \text { if } & p_{g}>p_{1}^{*} \\
\left(1, p_{g}-\epsilon\right) & \text { if } & p_{g} \in\left(p_{1}^{0}, p_{1}^{*}\right] \\
(0, p) & \text { if } & p_{g} \leq p_{1}^{0}
\end{array}\right.
$$

When government provision is low enough $(q<\bar{q})$, the firm will entertain the possibility of sharing the market with the government, so:

$$
\left(e^{*}, p^{*}\right)=\left\{\begin{array}{lll}
\left(1, p_{1}^{*}\right) & \text { if } & p_{g}>p_{1}^{*} \\
\left(1, p_{g}-\epsilon\right) & \text { if } & p_{g} \in\left(\tilde{p}(q), p_{1}^{*}\right] \\
\left(1, p_{3}^{*}(q)\right) & \text { if } & p_{g} \leq \tilde{p}(q)
\end{array}\right.
$$

Proposition 2 then characterises a profit-maximising firm's optimal strategy:

Proposition 2 A profit-maximising firm's optimal strategy is described by (13) for $q \geq \bar{q}$ and by (14) for $q<\bar{q}$.

\section{Proof}

The existence and uniqueness of $p_{1}^{*}, p_{3}^{*}(q), p_{1}^{0}$ and $\tilde{p}(q)$ follows from Lemmas 1,2 and 4 , and the assumption that $\pi^{1 *}>0$. The firm's maximum profit is earned when it prices at $p_{1}^{*}$ and captures the entire market. Since $\pi^{1 *}>0$, its optimal strategy will therefore clearly be to enter and offer a price of $p_{1}^{*}$ whenever it can capture the whole market by so doing. This explains the first part of both (13) and (14). By Lemma 3, entering and offering a price of $p^{*}=p_{g}$ is strictly dominated, so this rules out $p_{2}^{*}$. When $q \geq \bar{q}$, by Lemma 4 , we know it will never be profitable to enter and share the market with the government. This means that the firm will only enter the market when it captures the entire market and makes a profit in so-doing. For any $p<p_{1}^{0}$, the firm makes negative profits, so it will not enter when $p_{g} \leq p_{1}^{0}$, explaining the third line of (13). For $q>\bar{q}$ and $p_{g} \in\left(p_{1}^{0}, p_{1}^{*}\right]$, by contrast, captures the entire market by undercutting the government's price and entry is profitable, explaining the second line of (13). A similar line of argument holds for the second and third parts of (14) where $q<\bar{q}$; only the cutoffs change, following from Lemma 5. 
Figures 2 and 3 depict the equilibrium strategies described in Propositions 1 and 2. The solid line depicts the profit-maximiser's best response to a government price $p_{g}$, for a given level of government provision. The dashed line does the same for a non-profit.

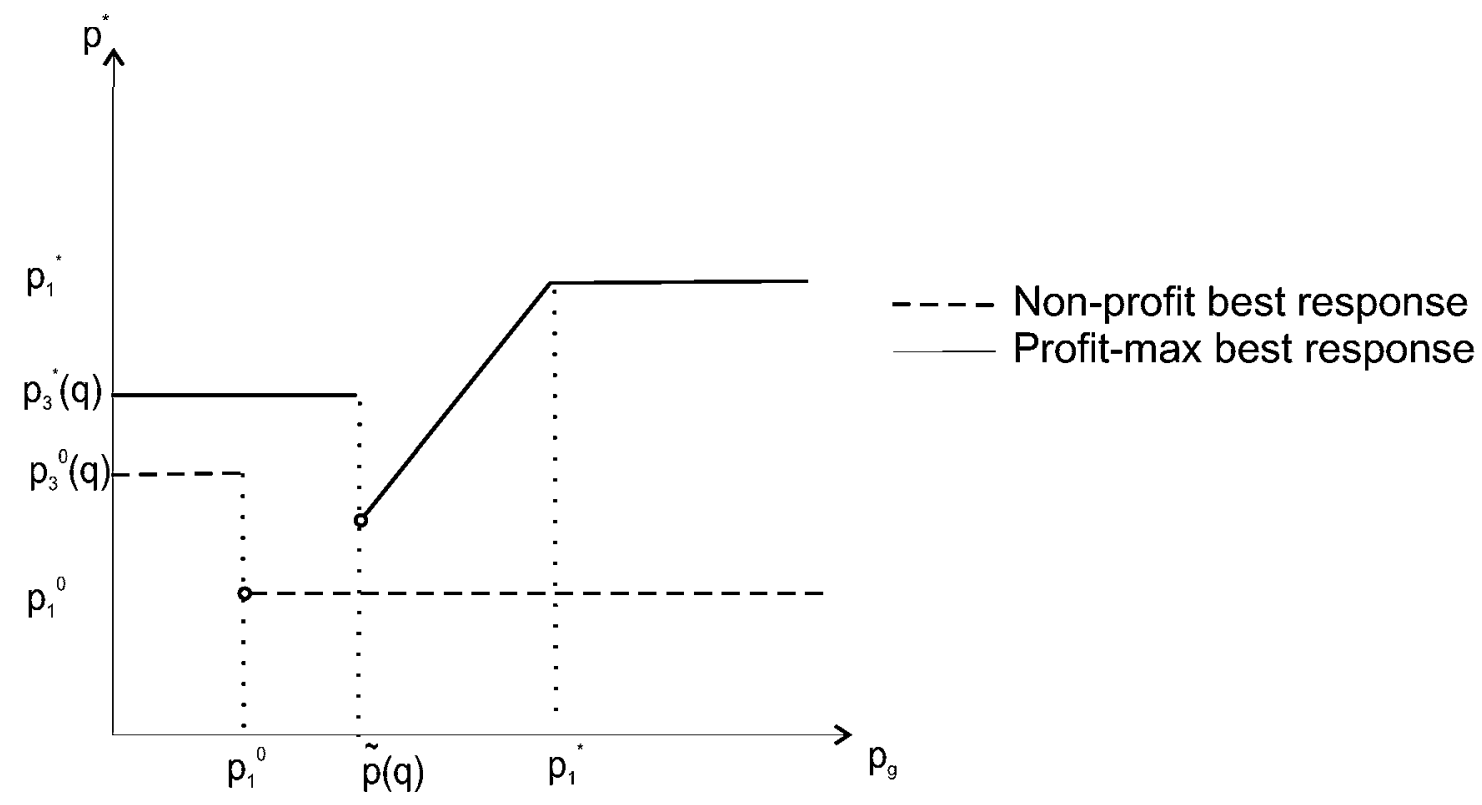

Figure 2: Equilibrium price strategies for low q

First consider Figure 2, where public provision is low $(q<\bar{q})$. When government prices are extremely high $\left(p_{g}>p_{1}^{*}\right)$, the firm will simply price at $p_{1}^{*}$ since in so doing, it is earning its highest possible profit, as depicted in Figure 1. When government prices are in an intermediate range $(\tilde{p}(q)<$ $\left.p_{g} \leq p_{1}^{*}\right)$, the profit-maximiser would earn higher profits by having the entire market to itself than sharing it (notice that in this range, the solid profit function is above the dashed one in Figure 1). In order to accomplish this, it just under cuts the government's price in this range, as depicted by the (slightly below) $45^{\circ}$ line. When government prices are sufficiently low, on the other hand $\left(p_{g} \leq \tilde{p}(q)\right)$, the firm will be better off just sharing the market with the government and charging a price $p_{3}^{*}(q)$ (where the maximum of a 
profit function such as the dashed one depicted in Figure 1 is reached).

The non-profit's strategy is even simpler: it will simply price as low as it possibly can without making a loss. From Figure 1, this is the point where the profit function intersects the $\mathrm{x}$-axis at the furthest point to the left. When the government's price is not subsidised $\left(p_{g}>p_{1}^{0}\right)$, it will therefore price at $p_{1}^{0}$. When the government's price is low, on the other hand $\left(p_{g} \leq p_{1}^{0}\right)$, for the firm to price any lower and command the entire market would entail making a loss. Instead, it will share the market with the government, pricing at $p_{3}^{0}(q)$.

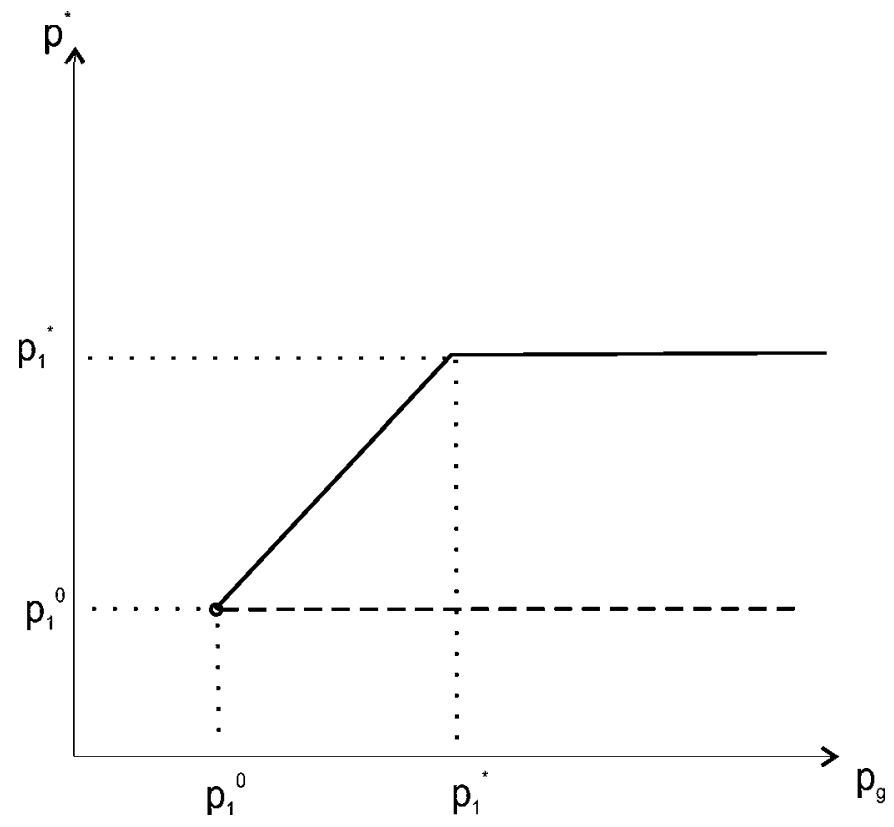

$\begin{array}{ll}--- & \text { Non-profit best response } \\ \end{array}$

Figure 3: Equilibrium price strategies for high q

Figure 3 is analogous to Figure 2, but depicts a high level of government provision $(q \geq \bar{q})$. The firm's pricing strategy for relatively high government prices are more or less identical to those described in Figure 2, with the cut-off point for the profit-maximiser's undercutting strategy now at $p_{1}^{0}$. The main difference is that when public provision is high and government prices 
are subsidised $\left(p_{g}<p_{1}^{0}\right)$, the firm chooses not to enter at all since it would not, have sufficient, demand to cover its costs.

\subsection{Discussion}

Propositions 1 and 2 suggest that one should observe three types of equilibria in a market with partial public provision of a private good $(q \in(0,1)$ or $\left.p_{g}>\underline{w}\right)$. In the first type of equilibrium, the government offers a limited quantity of the good at a relatively high price $\left(p_{g} \geq p_{1}^{0}\right.$ or $\left.p_{g} \geq \tilde{p}\right)$ and the firm, by offering a lower price, is the sole provider. This situation is tantamount to there being no government provision at all. It is therefore not terribly relevant, except for its suggestion that (quite aside from any distributive considerations) the government must offer subsidised provision in order to attract any demand in the presence of a potential non-profit or competitive private provider. Where the government is unwilling or unable to offer high levels of subsidised provision, one would expect to see only private providers in the market. This might provide a partial explanation for why, for example, most health care and child care services in the US are characterised by an absence of government provision.

The second type of equilibrium is one in which the government offers a subsidised price $\left(p_{g} \leq p_{1}^{0}\right)$, a relatively high level of provision $(q \geq \bar{q})$, and is the sole provider. This is a situation in which government provision completely crowds private provision. It is an apt description, for instance, of the day care markets in Sweden, Denmark and Finland (Kamerman, 2000), and primary schooling in many Indian villages (PROBE, 1999): the government does not cater to the entire population, and private providers are conspicuous in their absence. In the third type of equilibrium, the government offers a low price $\left(p_{g} \leq p_{1}^{0}\right.$ or $\left.p_{g} \leq \tilde{p}(q)\right)$ and a relatively low level of provision $(q \leq \bar{q})$, serving the market jointly with the private firm. This characterises the day care markets in Canada, the UK, Austria, Germany, Italy and Spain (Kamermann, 2000), numerous health care services in developing countries (Filmer, Hammer and Pritchett 2000, 2002), and schooling in numerous developing 
countries (James, 1993).

These two propositions also give a couple of (somewhat obvious) insights into why market structure matters. First, ceteris paribus, prices in the private sector are higher when these private services are offered by a profitmaximising monopolist than when they are offered by a non-profit (or in a competitive environment). Second, since $p_{1}^{0}<\tilde{p}$, when both the government and the private firm supply the market, the government can also sustain a higher price in the presence of a profit-maximiser than a non-profit. As we will see in the section below, with efficient rationing, this means not only that aggregate supply will be lower in a market with a profit-maximising monopolist and the government, but also that the consumer surplus will be smaller.

\section{Analysis}

The previous section provided a complete characterisation of the firm's best response to the government's price and given a particular quantity of government provision. In practice, governments which provide private goods usually do so at highly subsidised prices, well below any average cost. If the government and private firms have access to the same technologies, this is tantamount to the government posting a price of $p_{g}<p_{1}^{0}$. Given that in most countries we tend to see some government provision of such goods as day care, health care and schooling even when there exists the potential for perfect private substitutes, this makes sense in the context of the previous section.

For the remainder of this paper, therefore, we will restrict our attention to the case where $p_{g}<p_{1}^{0}$. In this section we present some comparative statics results and then see what implications a change in government provision has for aggregate access to the public good. 


\subsection{Comparative Statics}

When the government prices at a subsidised rate, the firm's entry and pricing strategy no longer varies with $p_{g}$. It does, however, vary with $q$, the income distribution $f(w)$, and costs $c$ and $B$-which can also be interpreted as the effect of government regulation (more stringent regulation being reflected in higher fixed or marginal costs). Proposition 3 establishes some comparative statics results for $\left(p_{g}, q\right)<\left(p_{1}^{0}, \bar{q}\right)$ :

Proposition 3 With efficient rationing, for $\left(p_{g}, q\right)<\left(p_{1}^{0}, \bar{q}\right), p_{3}^{*}(q) \quad\left(p_{3}^{0}(q)\right)$ is (i) decreasing (increasing) in q; (ii) increasing in the marginal cost $c$; (iii) unchanged (increasing) in the fixed cost $B$; and (iv) unchanged in $p_{q}$. (v) $\bar{q}$ is decreasing in $B$; (vi) if $\mu \in(-\infty, \infty)$ and $f(w-\mu)$ is the location family with standard pdf $f(w)$, then $\bar{q}$ is decreasing in $\mu$.

\section{Proof}

Since $q<\bar{q}$ there exists a unique interior solution to (7). For the profit-maximiser, taking the first order condition (FOC) for an interior solution to (7) yields $1-F(p)-q-f(p)(p-c)=0$. Taking the total derivative of this expression with respect to $q$ and $p$ yields

$$
\frac{d p}{d q}=\frac{-1}{2 f(p)+f^{\prime}(p)(p-c)}<0
$$

under assumption 2, accounting for (i). Similarly for (ii), taking the total derivative of the FOC with respect to $c$ and $p$ yields

$$
\frac{d p}{d c}=\frac{f(p)}{2 f(p)+f^{\prime}(p)(p-c)}>0
$$

under assumptions 1 and 2. Part (iii) also follows from casual inspection of the FOC. For the non-profit firm, the optimal price is $p_{3}^{0}=c+\frac{B}{1-F^{(}\left(p_{3}^{0}\right)-q}$. This expression is clearly increasing in $q, c$ and $B$. That $p_{1}^{0}$ and $p_{3}^{*}$ do not change with $p_{g}$ for $\left(p_{g}, q\right)<\left(p_{1}^{0}, \bar{q}\right)$ follows from propositions 1 and 2. For (v), note that $\pi^{3}(B)<\pi^{3}\left(B^{\prime}\right) \forall B<B^{\prime}$; the result then follows from Lemma 4. Finally, for (vi), observe that $\bar{q}=1-F\left(p_{3}^{*}+\mu\right)-\frac{B}{p_{3}^{*}-c}$. Since, by assumption $1, F^{\prime}>0$, this is clearly decreasing in $\mu$. 
Proposition 3 highlights several features of an environment in which a private good is only partially publicly provided at low levels and subsidised prices. First, for both a profit-maximising firm and a non-profit, higher marginal costs will result in higher prices. Second, increasing government provision, though remaining below the threshold $(\bar{q})$ has different implications for the price of private provision depending on the type of private provider in question. An increase in subsidised government provision results in a reduction in residual demand available to the private firm. Any such reduction will therefore increase the price charged by a non-profit, since it results in an increase in its average cost. A profit-maximiser, on the other hand, will wish to counteract the drop in its demand and this is can only be accomplished by lowering its price. An increase in $q$ therefore results in a decrease in a profit-maximiser's price, but an increase in a non-profit's price. Similarly, an increase in fixed costs (through, for instance, the imposition of more stringent regulation of private providers), does not alter the price offered by the profit-maximiser who, conditional upon entry, sets prices where marginal revenue equal to marginal cost. It does, however, increase the price of the non-profit, who prices at minimum average cost.

Third, increasing fixed costs has one further effect, which is to decrease the critical threshold below which firms will choose to enter and be willing to share the market with the government. This implies, unsurprisingly, that for a given $\left(p_{g}, q\right)$, private firms are less likely to be seen participating in a market with higher fixed costs. Furthermore, governments wishing to alter private provision from such a status quo cannot do so by reducing $p_{g}$, since doing so does not affect the price charged or quantity supplied of private firms. Finally, countries with lower returns to the consumption of the private good or a higher opportunity cost to non-consumption (both captured by a lower $\mu$ ) are less likely to have private firms entering the market. 


\subsection{Government Policy and Aggregate Provision}

More generally, when the government price is subsidised and rationing is efficient, aggregate provision of the private good in equilibrium is:

$$
A\left(p, q ; p_{g}<p_{1}^{0}\right)=\left\{\begin{array}{lll}
1-F\left(p_{3}(q)\right) & \text { if } & q<\bar{q} \\
\min \left\{q, 1-F\left(p_{g}\right)\right\} & \text { if } & q \geq \bar{q}
\end{array}\right.
$$

Equation (15) and proposition 3 provide some normative lessons regarding how a government which is publicly providing at a subsidised rate $\left(p_{g}<p_{1}^{0}\right)$, and is interested in increasing provision of the private good might go about accomplishing this goal in the most efficient possible manner. We assume throughout that the government has access to identical technology as the private sector.

First consider the case of a non-profit firm, which is illustrated in Figure 4. The first line of (15) refers to the case when $\left(p_{g}, q\right)<\left(p_{1}^{0}, \bar{q}\right)$. From proposition 3, increasing $q$ upto $\bar{q}$ only serves to increase $p_{3}^{0}$, and in so doing, the government is only really crowding out private provision and hindering aggregate access. This is underscored by noticing that if the government were to withdraw from the market altogether, aggregate provision would be $1-F\left(p_{1}^{0}\right)>1-F\left(p_{3}^{0}\right)$.

A government interested in ensuring aggregate provision $A \in\left(0,1-F\left(p_{1}^{0}\right)\right]$ would therefore be best advised to exit the market altogether. Not only would this increase aggregate provision, it would lead to a larger social surplus. More formally, suppose the government is providing $q \in(0, \bar{q})$ at a price $p_{g}<p_{1}^{0}$. Then, if $w^{\prime}$ solves $1-F(w)=q$, and $A C\left(w^{\prime}\right)$ is the average cost when demand is $1-F\left(w^{\prime}\right)$, the change in social surplus from the government exiting the market is:

$\int_{p_{1}^{0}}^{p_{3}^{0}}\left(w-p_{1}^{0}\right) f(w) d w+\int_{p_{3}^{0}}^{w^{\prime}}\left(p_{3}^{0}-p_{1}^{0}\right) f(w) d w+\left(A C\left(w^{\prime}\right)-p_{1}^{0}\right)\left(1-F\left(w^{\prime}\right)\right)>0$

The first expression represents the addition to consumer surplus from the increase in aggregate provision. The second expression captures the net gain to former private sector consumers from the reduction in price. The last 


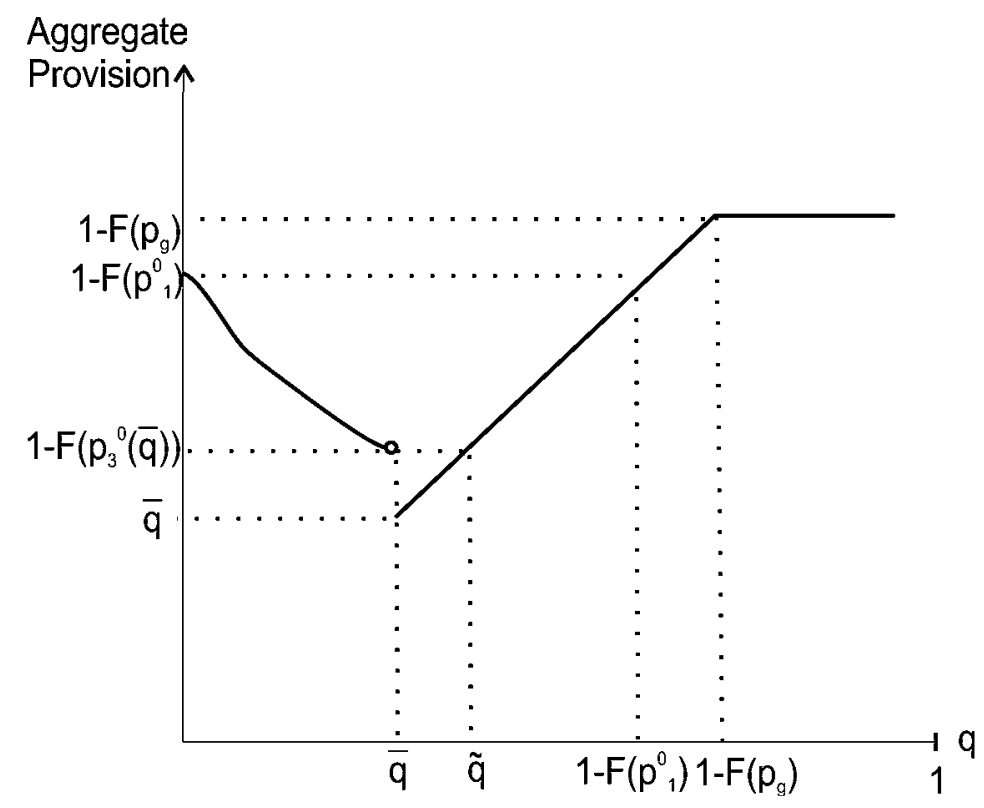

Figure 4: Aggregate provision with a non-profit firm

expression depicts the cost savings from having the segment of the population previously served by the government, served by the non-profit instead.

Note also, as depicted in Figure 4, that if $\tilde{q}=1-F\left(p_{3}(\bar{q})\right)$, the government should never provide at a level $q \in[\bar{q}, \tilde{q}]$ at a price $p_{g}<p_{1}^{0}$. In so doing, it dissuades the private non-profit from entering the market while simultaneously offering lower aggregate provision at a greater loss than if it offered $q<\bar{q}$.

The maximum provision a private non-profit firm would be willing to offer is $1-F\left(p_{1}^{0}\right)$. As alluded to in the introduction, however, there may be at least two reasons (neither of which we formally model here) why a government may wish to extend aggregate provision beyond this level. First, there may exist positive externalities from increasing aggregate provision. In the case of health care, this may for instance arise from the control of infectious disease and in the case of day care provision, these may accrue from having a higher rate of employment in the general population. Alterna- 
tively, the government may have political motivations in increasing provision above $1-F\left(p_{1}^{0}\right)$ : neither involuntary unemployment nor high morbidity help incumbents win elections.

With efficient rationing, expanding provision beyond this entails providing the good for a price $p^{\prime}<p_{1}^{0}$. As we have seen, for the government to offer such a price but provide at low levels only curtails aggregate access. In the absence of instruments other than direct provision, improving aggregate access beyond $1-F\left(p_{1}^{0}\right)$ therefore requires not only a subsidised price, but also public provision of $q>1-F\left(p_{1}^{0}\right)$, which completely crowds out private sector provision. Indeed, those OECD countries with the highest levels of child care provision - Finland, Denmark and Sweden - are all characterised by heavily subsidised prices, high levels of public provision, and a virtual absence of private sector participation (see Kamerman (2000) and Plantenga and Hansen (1999).)

As Figure 5 illustrates, things are slightly different when the private provider is a profit-maximising monopolist. When the government prices and provides at $\left(p_{g}, q\right)<\left(p_{1}^{0}, \bar{q}\right)$, aggregate provision, from the first line of (15), will be $1-F\left(p_{3}^{*}(q)\right)$. From Section 3.3, we know that this is less than $1-F\left(p_{1}^{0}\right)$, which is what provision would be with an analogous government policy in the presence of a non-profit. From proposition 3 it is clear that, contrary to the non-profit scenario, increasing government provision upto $\bar{q}$ will increase access by lowering $p_{3}^{*}$. From proposition 2 , we also notice that a withdrawal of government provision altogether would lead to a decrease in aggregate provision, since this would induce the profit-maximiser to price at $p_{1}^{*}>p_{3}^{*}$.

Whereas in the non-profit case, public provision at subsidised prices and low levels crowded out private provision and reduced aggregate provision. public provision in the face of a profit-maximiser acts as a moderating influence on private sector prices, thereby expanding aggregate provision. Canada and the US are two countries which have somewhat similar cost structures and in which private for-profit institutions are active in the day care market. 


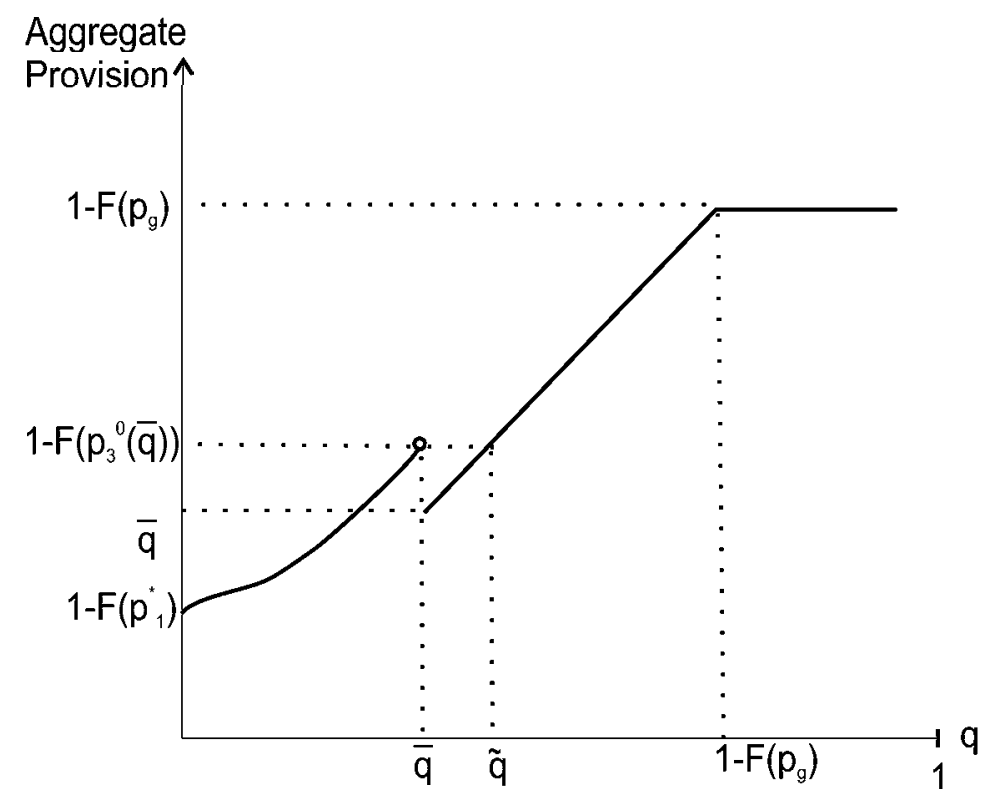

Figure 5: Aggregate provision with a profit-maximiser

They differ, however, in the extent of public provision, which is considerably higher in Canada relative to the US. This may, at least in part, explain why aggregate access tends to be higher there than in the US, with 45 per cent of 0-3 year olds in Canada attending day care compared to 26 per cent of the same age group in the US (Kamerman, 2000, p. 20-21).

Notice from proposition 3 that $p_{3}^{*}(q)$ is decreasing in $q$ for $q \in[0, \bar{q})$. From (15), it is clear that since $F(w)$ is increasing, aggregate provision with a profit-maximising private sector's involvement will be maximised at $\bar{q}-\epsilon$. Expanding provision beyond $1-F\left(p_{3}^{*}(\bar{q}-\epsilon)\right)$ entails making entry unprofitable for the private profit-maximiser and relegating provision entirely to the public realm (although, for reasons similar to those in the non-profit case, the government should never offer $q \in[\bar{q}, \tilde{q}])$. From the second line of (15), therefore, expanding provision beyond $1-F\left(p_{3}^{*}(\bar{q}-\epsilon)\right)$ entails subsidising prices even further if $q>1-F\left(p_{g}\right)$ and expanding public provision beyond $1-F\left(p_{3}^{*}(\bar{q})\right)$ otherwise. 


\section{The poor}

In the model described so far we have assumed that rationing of the private good is efficient, in that those who value the good most - those with the highest $w$-obtain access to it at the cheaper (government) rate. This was formalised in the demand functions described in (2). What this neglects, of course, is that in subsidising prices, governments tend to be motivated, at least in part, by enabling access to the private good among the poor: those who would not otherwise be able to afford it. There are innumerable ways in which the government goes about accomplishing this. These include income tax subsidies, income-indexed fee scales, and free or highly subsidised access to the poor. In developing countries where detailed income data are hard to come by, the last tends to predominate, whereas the first two are more common in developed countries.

Trying to characterise all the different ways in which the government attempts to target poorer families would be futile given their number and variety. In this section, therefore, we restrict our attention to two relatively common policies. In the first, the poor obtain free access to the publicly provided private good; this is common in developing countries with regard to health care provision. In India, for example, hospital care is, in principle. provided free of charge to the poor. The second policy we will consider is one in which the government provides tax subsidies to those who consume the good. In Canada and the US, for example, working mothers may tax deduct a portion of their childcare expenses.

\subsection{Free access for the poor}

Consider, first, the developing country prescription where the poor get free access to the publicly provided private good. If $W_{p}$ denotes the poverty line, then, $p_{q}=0$ for $W \leq W_{p}$ and $q \leq F\left(w_{p}\right)$, reflecting the fact that there tends to be no excess capacity in public provision. Suppose first, that targeting is perfect, so only the poorest get access to the free government provision. 
This means that if $F(\hat{w})=q$, only those with $w \leq \hat{w}$ have access to public provision. Demand for the private firm, is then:

$$
D(p)=\min \{1-F(p), 1-F(\hat{w})\}
$$

If it offers a price higher than $\hat{w}$, it captures the entire market with $w \geq p$ and if it offers a price less than $\hat{w}$, it gets only residual demand. When $\hat{w}<p_{1}^{0}$, or equivalently government provision is sufficiently scant, the private sector is unaffected. Aggregate access in this case will clearly be higher than in the absence of government provision. By targeting only the very poor, the government does not crowd out private sector demand, and aggregate provision in this case is $1+F(\hat{w})-F(p)$, where $p^{0}=p_{1}^{0}$ and $p^{*}=p_{1}^{*}$. Although the upper and lower ends of the income distribution would be served, those in the middle $\hat{w}<w<p$ will not have access to the private good. Since $p_{1}^{0}<p_{1}^{*}$, the segment of the population without access to the private good will be larger with a profit-maximiser than with a non-profit.

When $p_{1}^{0}<\hat{w}<p_{1}^{*}$, government provision will not affect the strategy of a profit-maximiser. However, it would increase average cost and therefore, the price charged by a non-profit. When $\hat{w} \geq p_{1}^{*}$, public provision will also affect private for-profit provision. In particular, the profit-maximiser will offer a price $\hat{w}$. Government provision beyond a certain threshold $\left(q>F\left(p_{1}^{0}\right)\right.$ for a non-profit and $q>F\left(p_{1}^{*}\right)$ for profit maximisers) therefore always increases private sector prices, even as it increases aggregate access, and when it is sufficiently high $\left(q \geq 1-\frac{B}{\bar{w}-c}\right)$, entry is unattractive to both types of firms.

Of course, targeting of the poor is rarely perfect. In developing countries in particular, it is often infeasible to target on the basis of income. The effect of government policy on aggregate provision obviously depends on who gets access to public provision and in both developing and industrialised countries. this is often determined by queuing, or just sheer luck.

One way of formalising this is through a proportional-rationing rule. Suppose, as in the previous example, $p_{g}=0$. Then, demand for the publicly provided good is $1-F(0)$. If we restrict our attention to the set of agents 
who would utilise the private good at non-negative prices by normalising $F(0)=0$, then under a proportional rationing rule, each individual will obtain access to the publicly provided good at zero cost with probability $q$ (and a proportion $q$ of the population will do so). This leaves an expected demand for the private firm of $(1-q)(1-F(p))$ and corresponding profit function of $\bar{\pi}=(1-q)(1-F(p))(p-c)-B$. In an analogous manner to $\bar{q}$ in Lemma 4 , it is not difficult to show that there exists a $q^{\prime} \in(0,1)$ above which a private firm will not enter the market. As such, it deters entry to a greater extent. ceteris paribus, than when targeting is perfect. However, since $q^{\prime}<\bar{q}$, it does not deter entry to the same extent as when rationing is efficient. Similar to the efficient rationing case, the price charged by a non-profit which chooses to enter is strictly increasing in $q$. By contrast, the price charged by a profit-maximiser may increase or decrease. More specifically, it will increase if $1-F\left(p_{1}^{*}\right)<f\left(p_{1}^{*}\right)\left(p_{1}^{*}-c\right)$ and will decrease otherwise.

\subsection{Tax break for users}

Now consider a second policy: one in which the government does not publicly provide, but consumers of the private good get lump-sum, price-indexed tax break. Suppose that $\tau \in(0,1)$ and the aggregate subsidy a consumer receives is $\tau p$. Since only those who utilise the private good are typically eligible for the subsidy (and recalling that $W$ denoted income net of tax), modifying equation (1) yields $\alpha=1$ if $w>(1-\tau) p((\alpha=0)$ if $(w \leq(1-\tau) p)){ }^{8}$. Since the government doesn't publicly provide, any aggregate provision will clearly be determined solely by the private sector. In particular, the aggregate demand for the private good provided by a private firm at price $p$ is $1-F((1-\tau) p)$, with an associated profit function of:

$$
\pi(\tau)=(1-F((1-\tau) p))(p-c)-B
$$

\footnotetext{
${ }^{8}$ Here, we are implicitly ruling out the case where the tax break is larger than the tax bill.
} 
Demand is clearly increasing in $\tau$, lowering average costs and $p^{0}=c+$ $\frac{B}{1-F\left((1-\tau)\left(p_{1}^{0}\right)\right)}$. When the private sector comprises a non-profit firm, therefore, such a policy increases aggregate (private) provision, even if the abject poor are only reached when $\tau \rightarrow 1$.

With a profit maximiser, an increase in $\tau$ may increase or decrease prices, and hence access. In particular, it will increase access if $2 f(\tau-1)(p))+f^{\prime}((\tau-$ 1) $(p))(p-c)>0$ and decrease access (by increasing the profit-maximiser's price) otherwise. ${ }^{9}$ In the latter case, when the net effect of the price increase on the one hand and a tax break on the other hand is ambiguous, a wellintentioned measure may well be counter-productive; it would not only leave the poorest unassisted, but may also hurt the non-poor.

\section{Conclusion}

Does the partial public provision of a private good help or hinder aggregate access? In the truest of economic traditions the answer is, "it depends". It depends on such things as the market structure in which the private sector operates, rationing rules, and the absolute level of government provision.

When rationing is efficient, an increase in public provision from a low initial level expands aggregate access when there is market concentration, by causing a decrease in the market price. By contrast, it causes an increase in the price offered by a non-profit, and thereby decrease in aggregate provision in this case. High levels of subsidised public provision crowd out private provision by deterring entry. At the lower end of this range, the crowding out results in a lower level of aggregate provision than allowing for some private provision would have done; beyond this, the government (as the sole

\footnotetext{
${ }^{9}$ Taking the first-order condition for an interior solution to (17) and differentiating this completely with respect to $\tau$ and $p$ yields $\frac{d p}{d \tau}=\frac{f((1-\tau) p)(2 p-c-(\tau-1) p}{(\tau-1)\left((\tau-1) f^{\prime}((\tau-1) p)(p-c)+2 f((\tau-1) p)\right)}$. The numerator is always greater than 0 for any interior $p^{*}$ and $\tau \in(0,1]$. The denominator is greater than 0 if $(\tau-1) f^{\prime}((\tau-1) p)(p-c)+2 f((\tau-1) p)<0$ and less than 0 if this expression is greater than 0 . We ignore the hairline scenario when this expression is equal to zero.
} 
provider) increases aggregate provision 1 to 1 by increasing public provision.

Low levels of free provision targeted only to the very poor does not affect private provision one way or another. Aggregate provision in this case will be higher with than without public provision and one would expect to see the rich, the poor, but not the middle classes served. High enough levels of targeted public provision, on the other hand, always increases private sector prices and as such can be regarded as a form of indirect redistribution from the rich to the poor. When targeting of the poorest is imperfect or simply ignored, results tend to be moderated versions of those under efficient rationing, with the exception that public provision may no longer temper a profit-maxiser's price. Although tax breaks tend not to reach the poorest unless they are large, lump-sum income subsidies always increase aggregate provision with a non-profit provider by expanding aggregate demand. This may or may not be true with a profit-maximising monopolist.

The main contribution of this paper is to insert a note of caution into well-intentioned government policies of increasing aggregate provision by expanding public provision. It also suggests that how much the government should publicly provide really depends on whom it wants to reach, and how large it wishes aggregate provision to be. Here, the political economy literature on positive issues regarding public provision can offer much guidance. For low optimal levels of provision, a government should avoid participating in the market at all. This is, of course problematic if it is concerned about access for the poor, but in this case, targeting becomes important. For high levels of provision, and in the absence of alternative instruments, the government may have no choice but to go it alone - publicly providing at high levels and completely crowding out the private sector.

Although we in this paper only considered public provision, this is obviously not the only instrument a government has at its disposal to expand aggregate provision of a private good. Subsidies (to either consumers or producers) are one obvious alternative. Another which this paper suggests is important is private sector regulation. Stringent regulation tends to trans- 
late into high fixed costs, high marginal costs, or both. These lead to higher prices, threaten to deter entry, and curtail aggregate access. Governments would do well, therefore, to consider any increased quality emanating from higher standards against its implications for aggregate access.

In concentrating on the partial public provision of private goods and the private sector's response, this paper did not address several important issues, one of which - alternative policy instruments - was just alluded to. Perhaps the most important of issue, however, is what warrants government intervention in this market in the first place. Within the context of this model, intervention may be warranted if gains in consumer surplus arising from increased provision more than compensate for losses on the part of the firm or government. More pertinent candidates are however, political or electoral motivations, or externalities. Modeling these explicitly would help to shed light on why the government wishes to achieve a given level of aggregate provision and what this optimal level is. Whether to rely on the public or private sector to achieve this would then be guided by the results in this paper. 


\section{Bibliography}

Andreoni, James (1993): "An Experimental Test of the Public-Goods

Crowding-Out Hypothesis", American Economic Review, 83(5), 1317-27.

Bernheim, Douglas B. (1986): "On the Voluntary and Involuntary

Provision of Public Goods", American Economic Review 76, 789-93

Besley, Timothy and Stephen Coate (1991): "Public Provision of Private Goods and the Redistribution of Income", American Economic Review 81(4), 979-984.

Blomquist, Sören and Vidar Christiansen (1999): "The Political Economy of Publicly Provided Private Goods", Journal of Public Economics, 73, $31-54$.

Daycare Trust (2001): The UK at the Crossroads towards an early years European partnership, London: Daycare Trust.

Epple, Dennis and Richard E. Romano (1996a): "Public Provision of Private Goods", Journal of Political Economy 104(1), 57-84.

Epple, Dennis and Richard E. Romano (1996b): "Ends Against the Middle: Determining Public Provision When There are Private Alternatives", Journal of Public Economics, 62(3), 297-326.

Filmer, Leon, Jeffery S. Hammer and Lant H. Pritchett (2000): "Weak Links in the Chain: A Diagnosis of Health Policy in Poor Countries", World Bank Research Observer15(2), 199-224.

Filmer, Leon, Jeffery S. Hammer and Lant H. Pritchett (2002): "Weak Links in the Chain II: A Prescription for Health Policy in Poor Countries", World Bank Research Observer 17(1), 47-66. 
Friedman, Milton (1962): Capitalism and Freedom, Chicago: University of Chicago.

James, Estelle (1993): "Why Do Different Countries Choose a Different Mix of Public-Private Services?" Journal of Human Resources, 28(3), 571-92.

Jimenez, Emmanuel and Yasuyuki Sawada (2001): "Public for Private: Relationship between Private and Private School Enrollment in the Phillipines", Economics of Education Review, 20, 389-99.

Kamerman, Sheila B. (2000): "Early Childhood Education and Care: An Overview of Developments in OECD Countries", International Journal of Educational Research 33, 7-29.

Plantenga, Janneke and Johan Hansen (1999): “Assessing Equal Opportunities in the European Union", International Labour Review, 138(4), 359-371.

Public Report on Basic Education in India (PROBE) (1999), New Delhi: Oxford.

Shmanske, Stephen (1996): "Contestability, Queues, and Governmental Entry Deterrence", Public Choice, 86(1), 1-15.

Tirole, Jean (1988): The Theory of Industrial Organization, Cambridge: MIT Press. 


\section{CESifo Working Paper Series}

(for full list see www.cesifo.de)

743 Robert Fenge, Silke Uebelmesser, and Martin Werding, Second-best Properties of Implicit Social Security Taxes: Theory and Evidence, June 2002

744 Wendell Fleming and Jerome Stein, Stochastic Optimal Control, International Finance and Debt, June 2002

745 Gene M. Grossman, The Distribution of Talent and the Pattern and Consequences of International Trade, June 2002

746 Oleksiy Ivaschenko, Growth and Inequality: Evidence from Transitional Economies, June 2002

747 Burkhard Heer, Should Unemployment Benefits be Related to Previous Earnings?, July 2002

748 Bas van Aarle, Giovanni Di Bartolomeo, Jacob Engwerda, and Joseph Plasmans, Staying Together or Breaking Apart: Policy-makers' Endogenous Coalitions Formation in the European Economic and Monetary Union, July 2002

749 Hans Gersbach, Democratic Mechanisms: Double Majority Rules and Flexible Agenda Costs, July 2002

750 Bruno S. Frey and Stephan Meier, Pro-Social Behavior, Reciprocity or Both?, July 2002

751 Jonas Agell and Helge Bennmarker, Wage Policy and Endogenous Wage Rigidity: A Representative View From the Inside, July 2002

752 Edward Castronova, On Virtual Economies, July 2002

753 Rebecca M. Blank, U.S. Welfare Reform: What's Relevant for Europe?, July 2002

754 Ruslan Lukach and Joseph Plasmans, Measuring Knowledge Spillovers Using Patent Citations: Evidence from the Belgian Firm's Data, July 2002

755 Aaron Tornell and Frank Westermann, Boom-Bust Cycles in Middle Income Countries: Facts and Explanation, July 2002

756 Jan K. Brueckner, Internalization of Airport Congestion: A Network Analysis, July 2002

757 Lawrence M. Kahn, The Impact of Wage-Setting Institutions on the Incidence of Public Employment in the OECD: 1960-98, July 2002

758 Sijbren Cnossen, Tax Policy in the European Union, August 2002

759 Chandima Mendis, External Shocks and Banking Crises in Developing Countries: Does the Exchange Rate Regime Matter?, August 2002 
760 Bruno S. Frey and Lars P. Feld, Deterrence and Morale in Taxation: An Empirical Analysis, August 2002

761 Lars Calmfors and Åsa Johansson, Nominal Wage Flexibility, Wage Indexation and Monetary Union, August 2002

762 Alexander R. W. Robson and Stergios Skaperdas, Costly Enforcement of Property Rights and the Coase Theorem, August 2002

763 Horst Raff, Preferential Trade Agreements and Tax Competition for Foreign Direct Investment, August 2002

764 Alex Cukierman and V. Anton Muscatelli, Do Central Banks have Precautionary Demands for Expansions and for Price Stability? - Theory and Evidence, August 2002

765 Giovanni Peri, Knowledge Flows and Knowledge Externalities, August 2002

766 Daniel Friedman and Nirvikar Singh, Equilibrium Vengeance, August 2002

767 Sam Bucovetsky and Michael Smart, The Efficiency Consequences of Local Revenue Equalization: Tax Competition and Tax Distortions, August 2002

768 Tapio Palokangas, International Labour Market Regulation and Economic Growth with Creative Destruction, August 2002

769 Rudi Dornbusch, The New International Architecture, September 2002

770 Hans-Werner Sinn, Weber's Law and the Biological Evolution of Risk Preferences: The Selective Dominance of the Logarithmic Utility Function, September 2002

771 Thomas Mayer, The Macroeconomic Loss Function: A Critical Note, September 2002

772 Seppo Honkapohja and Kaushik Mitra, Learning Stability in Economies with Heterogenous Agents, September 2002

773 David Laidler, Inflation Targets Versus International Monetary Integration - A Canadian Perspective, September 2002

774 Morten I. Lau, Panu Poutvaara, and Andreas Wagener, The Dynamic Cost of the Draft, September 2002

775 Steven Brakman, Harry Garretsen, and Charles van Marrewijk, Locational Competition and Agglomeration: The Role of Government Spending, September 2002

776 Anke S. Kessler and Christoph Lülfesmann, The Theory of Human Capital Revisited: On the Interaction of General and Specific Investments, September 2002

777 Kjell Erik Lommerud, Frode Meland and Lars Sørgard, Unionized Oligopoly, Trade Liberalization and Location Choice, September 2002 
778 Antonio Merlo and François Ortalo-Magné, Bargaining over Residential Real Estate: Evidence from England, September 2002

$779 \mathrm{Yu}-\mathrm{Fu}$ Chen and Michael Funke, Exchange Rate Uncertainty and Labour Market Adjustment under Fixed and Flexible Exchange Rates, September 2002

780 Michael S. Michael, International Migration, Income Taxes and Transfers: A Welfare Analysis, September 2002

781 Clemens Fuest and Alfons Weichenrieder, Tax Competition and Profit Shifting: On the Relationship between Personal and Corporate Tax Rates, October 2002

782 Jan Bouckaert and Hans Degryse, Softening Competition by Enhancing Entry: An Example from the Banking Industry, October 2002

783 Johann K. Brunner and Susanne Pech, Adverse Selection in the Annuity Market with Sequential and Simultaneous Insurance Demand, October 2002

784 Gregory D. Hess and Eduard Pelz, The Economic Welfare Cost of Conflict: An Empirical Assessment, October 2002

785 Jan Erik Askildsen, Uwe Jirjahn, and Stephen C. Smith, Works Councils and Environmental Investment: Theory and Evidence from German Panel Data, October 2002

786 Geir H. Bjønnes, Dagfinn Rime, and Haakon O. Aa. Solheim, Volume and Volatility in the FX-Market: Does it matter who you are?, October 2002

787 John Evans and John Fingleton, Entry Regulation and the Influence of an Incumbent Special Interest Group, October 2002

788 Wolfgang Ochel, International Comparisons and Transfer of Labour Market Institutions, October 2002

789 B. Gabriela Mundaca, Moral Hazard Effects of Bailing out under Asymmetric Information, October 2002

790 Gene M. Grossman and Edwin L.-C. Lai, International Protection of Intellectual Property, October 2002

791 John Hassler, José V. Rodriguez Mora, Kjetil Storesletten, and Fabrizio Zilibotti, A Positive Theory of Geographic Mobility and Social Insurance, October 2002

792 Paul De Grauwe and Marianna Grimaldi, The Exchange Rate in a Model with Heterogeneous Agents and Transactions Costs, October 2002

793 Guido Friebel and Mariassunta Giannetti, Fighting for Talent: Risk-shifting, Corporate Volatility, and Organizational Change, October 2002 
794 Jan Erik Askildsen, Badi H. Baltagi, and Tor Helge Holmås, Will Increased Wages Reduce Shortage of Nurses? A Panel Data Analysis of Nurses' Labour Supply, October 2002

795 Marko Köthenbürger and Panu Poutvaara, Social Security Reform and Intergenerational Trade: Is there Scope for a Pareto-Improvement?, October 2002

796 Paul De Grauwe and Laura Rinaldi, A Model of the Card Payment System and the Interchange Fee, October 2002

797 Volker Böhm and Tomoo Kikuchi, Dynamics of Endogenous Business Cycles and Exchange Rate Volatility, October 2002

798 Mariam Camarero, Javier Ordóñez, and Cecilio Tamarit, The Euro-Dollar Exchange Rate: Is it Fundamental?, October 2002

799 Misa Tanaka, How Do Bank Capital and Capital Adequacy Regulation Affect the Monetary Transmission Mechanism?, October 2002

800 Jörg Baten and Andrea Wagner, Autarchy, Market Disintegration, and Health: The Mortality and Nutritional Crisis in Nazi Germany, 1933-1937, October 2002

801 Saku Aura, Uncommitted Couples: Some Efficiency and Policy Implications of Marital Bargaining, October 2002

802 Wolfram F. Richter, Delaying Integration of Immigrant Labor for the Purpose of Taxation, October 2002

803 Gil S. Epstein and Shmuel Nitzan, The Politics of Randomness, October 2002

804 John Hassler and José V. Rodriguez Mora, Should UI Benefits Really Fall over Time?, October 2002

805 Friedrich Breyer and Stefan Felder, The Dead-anyway Effect Revis(it)ed, October 2002

806 Assar Lindbeck and Solveig Wikström, E-exchange and the Boundary between Households and Organizations, November 2002

807 Dieter Bös, Contests Among Bureaucrats, November 2002

808 Steven Brakman, Harry Garretsen, and Marc Schramm, The Strategic Bombing of German Cities during World War II and its Impact on City Growth, November 2002

809 Florian Englmaier and Achim Wambach, Contracts and Inequity Aversion, November 2002

810 Sarbajit Sengupta, Delegating Recruitment under Asymmetric Information, December 2002

811 Rajshri Jayaraman, On the Partial Public Provision of a Private Good, December 2002 